\title{
HMGB1 induces apoptosis and EMT in association with increased autophagy following $\mathrm{H} / \mathrm{R}$ injury in cardiomyocytes
}

\author{
FAN OUYANG $^{1,2}$, HE HUANG $^{1,2}$, MINGYU ZHANG $^{2}$, MINGXIAN CHEN $^{2}$, \\ HAOBO HUANG $^{2}$, FANG HUANG ${ }^{2,3}$ and SHENGHUA ZHOU ${ }^{2}$ \\ ${ }^{1}$ Department of Cardiology, Xiangtan Central Hospital, Xiangtan, Hunan 411100; \\ ${ }^{2}$ Department of Cardiology, The Second Xiangya Hospital of Central South University, Changsha, Hunan 410011; \\ ${ }^{3}$ Department of Cardiology, The First Hospital of Changsha, Changsha, Hunan 410005, P.R. China
}

Received July 11, 2015; Accepted December 8, 2015

DOI: $10.3892 / \mathrm{ijmm} .2016 .2474$

\begin{abstract}
Hypoxia/reoxygenation (H/R) is a critical factor in the pathogenesis of tissue injury following myocardial infarction (MI) which can lead to tissue damage and pathological remodeling. Therefore, it is necessary to try and prevent myocardial H/R injury in order to optimize the treatment of MI. This study aimed to explore the functions and molecular mechanisms of action of high mobility group box 1 (HMGB1) and its role in $\mathrm{H} / \mathrm{R}$ injury to $\mathrm{H} 9 \mathrm{c} 2$ cells. The mRNA expression of levels genes were detected by RT-qPCR. The protein levels were examined by western blot analysis. The Beclin 1 expression level was further determined by immunocytochemistry (ICC). In addition, an HMGB1 overexpression vector and a shRNA lentiviral vector were constructed in order to induce the overexpression and silencing of HMGB1, respectively. The apoptotic rate of the $\mathrm{H} 9 \mathrm{c} 2$ cells was determined by flow cytometry. The expression of miR-210 was markedly increased following the exposure of the cells to $H / R$, thus indicating that the cell model of $\mathrm{H} / \mathrm{R}$ injury was successfully established. In addition, an in vivo model of MI was also created using rats. The mRNA and protein level of HMGB1 was found to be upregulated in the myocardial tissue of the rats with $\mathrm{MI}$ and in the H9c2 cells subjected to H/R injury. HMGB1 promoted apoptosis by increasing the expression of cleaved caspase-3 and the apoptotic rate of the cells, while decreasing the expression of Bcl-2 during $\mathrm{H} / \mathrm{R}$ in the $\mathrm{H} 9 \mathrm{c} 2$ cells. HMGB1 promoted epithelial-to-mesenchymal transition (EMT) by reducing the protein level of the epithelial marker, E-cadherin, while increasing the expression of the mesenchymal markers, vimentin and fibroblast-specific protein (FSP), during $\mathrm{H} / \mathrm{R}$ in
\end{abstract}

Correspondence to: Dr Fan Ouyang, Department of Cardiology, Xiangtan Central Hospital, 120 Heping Road, Xiangtan, Hunan 411100, P.R. China

E-mail: 1641261977@qq.com

Key words: high mobility group box 1, autophagy, apoptosis, epithelial-to-mesenchymal transition, hypoxia/reoxygenation injury the H9c2 cells. HMGB1 induced the apoptosis of the H9c2 cells and EMT following $\mathrm{H} / \mathrm{R}$ in association with the induction of autophagy. HMGB1 induced autophagy by upregulating the expression of discoidin domain receptor 1 (DDR1) and downregulating the phosphorylation levels of mammalian target of rapamycin (mTOR). In conclusion, the findings of our study suggest that HMGB1 promotes apoptosis and EMT in association with the induction of autophagy through the upregulation of the expression of DDR1 and the downregulation of the phosphorylation of mTOR following $\mathrm{H} / \mathrm{R}$ injury in $\mathrm{H} 9 \mathrm{c} 2$ cells.

\section{Introduction}

Myocardial infarction (MI), also known as a 'heart attack', results from a reduction in coronary blood flow which is extensive enough to render the oxygen supply to myocardial tissues insufficient $(1,2)$. Ischemia and consequent oxygen shortage, if left untreated for a long period of time, can cause myocardial cell death and necrosis (3-5). MI remains a leading cause of morbidity and mortality among all cardiovascular diseases in both developed and developing countries (6-8). Successful reperfusion therapy for MI can prevent heart failure, leading to reduced mortality (9-11). However, a side-effect of this therapy is myocardial ischemia/reperfusion (I/R), which can lead to tissue damage and pathological remodeling $(9,10)$. Furthermore, I/R injury is a critical factor in the pathogenesis of tissue injury following MI, multiple organ failure and other acute ischemic events (11). Therefore, it is necessary to try and prevent myocardial I/R injury as an adjunct therapy for the treatment of MI. As an important in vitro model for myocardial $\mathrm{I} / \mathrm{R}$ injury, hypoxia/reoxygenation $(\mathrm{H} / \mathrm{R})$ is similar to myocardial I/R (12), and is one of the cellular stresses in pathological conditions, such as MI (13). Thus, it is imperative to explore the molecular mechanisms responsible for $H / R$ injury and to identify possible treatment targets with which to prevent $H / R$ injury in cardiomyocytes.

High mobility group box 1 (HMGB1, also known as amphoterin) is an abundantly occurring parental form of HMG proteins and an exceptional member of the family of HMG-box proteins $(14,15)$. Dependent on the cell type and its activation state, HMGB1 exhibits a non-nuclear localization and is secreted from cells, in contrast to the majority 
of HMG-box proteins that are strictly bound to the cell nuclei $(16,17)$. HMGB1 can be passively released from injured cells $(15,16)$, and has been implicated in the development of MI by a number of studies (18-21). Over the past few years, studies have demonstrated that HMGB1 functions as an extracellular signaling molecule (22) that can promote autophagy in multiple biological processes, such as under conditions of oxidative stress $(23,24)$. It has been reported that autophagy is enhanced during myocardial I/R injury (25). However, another study suggested that although autophagy exerts protective effects during ischemia, it plays a detrimental role during reperfusion (26). Thus, the ambiguous role of autophagy in myocardial H/R injury remains to be elucidated, and whether HMGB1-mediated autophagy is involved in the development of myocardial H/R injury remains largely unclear. Therefore, in the present study, we evaluated the effects of HMGB1-mediated autophagy on the apoptosis of H9c2 cells and on epithelial-tomesenchymal transition (EMT). In addition, we investigated the molecular mechanisms responsible for these effects during myocardial $\mathrm{H} / \mathrm{R}$ injury.

\section{Materials and methods}

Cell culture and treatment. The cardiomyocyte cell line, H9c2 cells was obtained from the American Type Culture Collection (ATCC; Manassas, VA, USA). The cells were cultured in DMEM medium containing 10\% fetal bovine serum (FBS) and $1 \%$ antibiotic-antimycotic solution $(100 \mathrm{U} / \mathrm{ml}$ penicillin and $100 \mu \mathrm{g} / \mathrm{ml}$ streptomycin). The cells were maintained at $37^{\circ} \mathrm{C}$ in a humidified atmosphere containing $5 \% \mathrm{CO}_{2}$. Furthermore, the cells were treated with 3-MA (Selleck Chemicals, TX, USA), an autophagy inhibitor, in order to determine whether the autophagy process is involved in H/R injury. In addition, as an inhibitor of mammalian target of rapamycin (mTOR), OSI-027 (Selleck Chemicals, TX, USA) was added to the cells to observe the function of mTOR signaling.

Construction of a cell model of H/R injury using $H 9 c 2$ cells. The exposure of the cells to $H / R$ was performed as previously described in the study by Cao et al (9). Hypoxia was achieved by placing the $\mathrm{H} 9 \mathrm{c} 2$ cells in a hypoxia chamber filled with $5 \% \mathrm{CO}_{2}$ and $95 \% \mathrm{~N} 2$ at $37^{\circ} \mathrm{C}$ for $4 \mathrm{~h}$. Following exposure to hypoxia, the cells were reoxygenated with $5 \% \mathrm{CO}_{2}$ and $95 \%$ air for $3 \mathrm{~h}$ in DMEM with $10 \%$ FBS. Cells not subjected to $H / R$ were used as the negative controls.

Construction of rat animal model of $H / R$ injury. A total of 40 male Sprague-Dawley rats (weighing $320 \pm 20$ g) were obtained from the Experimental Animal Center of the Second Xiangya Hospital of Central South University, Changsha, China. All animal experiments were performed in accordance with the National Institutes of Health Guidelines on the Use of Laboratory Animals and were approved by the Ethics Committee of the Second Xiangya Hospital. The rats were kept in plastic cages and had access to pelleted food and water ad libitum. They were kept under standard laboratory conditions (12-h light/dark cycle, controlled temperature of $20-22^{\circ} \mathrm{C}$ ). The rats were anesthetized with pentobarbital sodium (50 mg, intraperitoneal), and intubated and ventilated with $100 \%$ oxygen. The chest was opened via a left thoracotomy through the fourth or fifth intercostal
Table I. Forward and reverse primer sequences of targeted genes.

\begin{tabular}{|c|c|c|}
\hline Gene & Name & Sequence \\
\hline \multirow[t]{2}{*}{ HMGB1 } & Sense & GATGGGCAAAGGAGATCCTA \\
\hline & Antisense & CTTGGTCTCCCCTTTGGGGG \\
\hline \multirow[t]{2}{*}{ DDR1 } & Sense & ATGGAGCAACCACAGCTTCTC \\
\hline & Antisense & CTCAGCCGGTCAAACTCAAACT \\
\hline \multirow{2}{*}{$\begin{array}{l}\text { Cleaved } \\
\text { caspase-3 }\end{array}$} & Sense & GAGCTGCCTGTAACTTG \\
\hline & Antisense & ACCTTTAGAACATTTCCACT \\
\hline \multirow[t]{2}{*}{ Bcl-2 } & Sense & TTGCCACGGTGGTGGAGGAAC \\
\hline & Antisense & GACAGCCAGGAGAAATCAAACAGA \\
\hline \multirow[t]{2}{*}{$\beta$-actin } & Sense & AGGGGCCGGACTCGTCATACT \\
\hline & Antisense & GGCGGCACCACCATGTACCCT \\
\hline
\end{tabular}

HMGB1, high mobility group box 1; DDR1, discoidin domain receptor 1 .

space and the hearts were exposed. An 8-0 silk ligature was placed under the left coronary artery (LCA) and tied using a shoestring knot. MI was confirmed by the presence of discoloration of the ischemic area, left ventricular (Lv) dyskinesia and ST-segment elevation on an electrocardiogram. Following occlusion for $30 \mathrm{~min}$, reperfusion was initiated by releasing the knot. Reperfusion was confirmed by the return of color to the ischemic area. The loosened suture was left in place and then retied for the purpose of evaluating the ischemic area. The chest wall was closed, the animal extubated and body temperature maintained by the use of a $37^{\circ} \mathrm{C}$ warm plate. In the shamoperated animals, the same procedure was performed with the exception of the coronary artery ligation. Following reperfusion, the rats were sacrificed by femoral artery bloodletting following anesthetization, and the rat hearts were harvested using surgical scissors. The cardiac base and cardiac apex tissue was separated for morphological analysis and molecular biological detection, respectively at 0,1 and 2 weeks post-MI.

Reverse transcription-quantitative PCR (RT-qPCR). Total RNA was extracted from the cells and heart tissue using TRIzol reagent (Invitrogen, Carlsbad, CA, USA) and the cDNA was reverse transcribed as the protocol for the reverse transcription system (Fermentas, Burlington, ON, Canada). The amplification primers were designed using Primer 5.0 with melting temperatures at $58^{\circ} \mathrm{C}$. The forward and reverse sequences of the primers used are presented in Table I. Quantitative PCR (qPCR) was performed using SYBR-Green qRCR (Toyobo, Osaka, Japan) in order to determine the mRNA expression levels of various genes [HMGB1, miR-210, cleaved caspase-3, Bcl-2 and discoidin domain receptor 1 (DDR1)] according to the manufacturer's instructions. Three repetitions were performed for qRT-PCR. The relative $\mathrm{mRNA}$ levels were normalized to those of $\beta$-actin mRNA, and were evaluated using the $2^{-\Delta \Delta \mathrm{Ct}}$ method.

Western blot analysis. Protein extracts from the H9c2 cells were prepared using RIPA Lysis buffer (Auragene Bioscience Co., Changsha, China) following the manufacturer's instructions. The protein concentration was determined according to the Bradford Protein assay reagent (Beyotime Institute of Biotechnology, 
Shanghai, China) using bovine serum albumin as a standard. Western blot analysis was subsequently carried out in order to detect the protein levels of HMGB1, cleaved caspase-3, Bcl-2, Beclin 1, light chain 3 (LC3)-II/I and DDR1. Equal amounts of lysate were resolved by sodium dodecyl sulfate-polyacrylamide gel electrophoresis (SDS-PAGE) and transferred onto PVDF membranes (Millipore, Bedford, MA, USA) using a semi-dry transfer method. The membranes were blocked with 5\% non-fat milk in TBST buffer at room temperature for $2 \mathrm{~h}$ and then incubated overnight with the following primary antibodies: HMGB rabbit polyclonal antibody (1:1,000; sc-33199; Santa Cruz Biotechnology, Inc. Dallas, TX, USA), cleaved caspase-3 rabbit polyclonal antibody $(1: 1,000 ;$ sc-22171-R, Santa Cruz Biotechnology, Inc.), Bcl-2 rabbit polyclonal antibody (1:800; sc-492; Santa Cruz Biotechnology, Inc.), E-cadherin mouse monoclonal antibody (1:800; BM0339; Abzoom, Dallas, TX, USA), vimentin mouse monoclonal antibody $(1: 1,000$; sc-32322; Santa Cruz Biotechnology, Inc.), fibroblast-specific protein (FSP) rabbit polyclonal antibody (1:1,500; orb89918; Biocompare, South San Francisco, CA, USA), Beclin rabbit monoclonal antibody $(1: 1,000 ; 2026-1$; Epitomics, Burlingame, CA, USA), LC3B rabbit polyclonal antibody (1:1,000; ab51520; Abcam, Hong Kong, China), p62 rabbit polyclonal antibody (1:1,000; ab96134; Abcam) and DDR1 rabbit polyclonal antibody (1:1,000; sc-532; Santa Cruz Biotechnology, Inc.). The membranes were then incubated for $1 \mathrm{~h}$ with the appropriate secondary antibodies (goat anti-rabbit antibody, 1:2,000; 111-035-003; goat anti-mouse antibody, 1:2,000; 111-035-008; Jackson Immunoresearch, Inc., West Grove, PA, USA; and donkey anti-goat antibody, 1:2,000; CW0214; CWBio, Beijing, China). Electrochemiluminescence was performed with an IPP6.0 system.

Immunocytochemistry (ICC). The $\mathrm{H} 9 \mathrm{c} 2$ cells were washed with phosphate-buffered saline (PBS) 3 times and fixed for $30 \mathrm{~min}$ in $4 \%$ paraformaldehyde. At that point, the cells were permeabilized for 15 min with PBS containing 0.3\% Triton X-100, and treated with $3 \% \mathrm{H}_{2} \mathrm{O}_{2}$ for 30 min followed by goat serum (Auragene Bioscience Co.) for $10 \mathrm{~min}$, and then incubated with Beclin 1 monoclonal antibody (1:500; 2026-1; Epitomics) overnight at $4^{\circ} \mathrm{C}$. Following 3 rinses with PBST, the cells were incubated for $30 \mathrm{~min}$ with the secondary antibody (donkey anti-goat, 1:1,000; CW0218, CWBio) and for a further $30 \mathrm{~min}$ with SABC complex (both from Auragene Bioscience Co.) at room temperature. Following 3 additional PBST rinses, the immunoreactive cultured cells were observed.

Construction of HMGB1 overexpression lentiviral vector. Primers were designed using the HMGB1 sequence in GenBank, which contained the HindIII and EcoRI restriction enzymes sites. The forward primer was 5'-cccAAGCTTA TGGGCAAAGGAGATCCTA-3', and the reverse primer was 5'-ccgGAATTCTTATTCATCATCATCATCT-3'. Rat myocardium genomic DNA was used as the template and RT-PCR was used to clone the HMGB1 gene. The RT-PCR products were resolved by $1 \%$ agarose gel electrophoresis, and then were purified, sequenced and cloned into the lentiviral vector, pCD513B-1, to produce the HMGB1 overexpression lentiviral vector (Lv-HMGB1). An empty vector was used as the negative control for HMGB1 (Lv-NC).
Construction of HMGB1 shRNA lentiviral vector. The mRNA sequence of HMGB1 shRNA was designed using online software (https://rnaidesigner.invitrogen.com/rnaiexpress/). The RNAi candidate target sequence was CCGGCTGCTTAGTTTAGGGAA CACTCGAGTGTTCCCTAAACTAAGCAGTTTTTTg, AATT CAAAAAACTGCTTAGTTTAGGGAACACTCGAGTGTT CCCTAAACTAAGCAG. A negative control shRNA containing a scrambled sequence with the same nucleotide composition was also selected and termed Lv-shRNA-scr. The shRNA-annealed oligonucleotides were ligated into the lentiviral vector,pCD513B-1, to construct the HMGB1 shRNA lentiviral vector (Lv-HMGB1shRNA) by T4 DNA ligase (Takara, Dalian, China). All constructs were verified by sequence analysis.

Cell transfection. The cells were transfected with the lentiviral vector carrying HMGB1 shRNA (Lv-HMGB1-shRNA) or with the HMGB1 overexpression lentiviral vector (Lv-HMGB1), or with the respective negative control vectors [Lv-NC or the scramble shRNA vector (Lv-shRNA-scr)]. The cells were transfected using Lipofectamine 2000 (Life Technologies/ Thermo Fisher Scientific, Grand Island, NY, USA) according to manufacturer's instructions. Untransfected cells were used as the controls (Con).

Transcription activator-like effector nuclease (TALEN)mediated knockdown of the DDR1 gene in H9c2 cells. We also used TALEN technology to knockdown the DDR1 gene in the H9c2 cells. TALENs designed to target the DDR1 gene were purchased from Sidansai Biotechnology Co., Ltd. (Shanghai, China). The cells in 24-well plates were transfected with 400 ng TALEN expression plasmids (DDR1-TALEN) using Lipofectamine 2000 (Invitrogen Life Technologies), according to the manufacturer's instructions. Western blot analysis was performed to measure the protein expression levels of DDR 1 and to confirm the efficiency of the TALEN-mediated knockdown.

Flow cytometry. The H9c2 cells were washed twice with cold PBS and then resuspended in $500 \mu \mathrm{l}$ pre-cooled binding buffer. The cells were subsequently stained with Annexin V-FITC and propidium iodide (PI) according to the protocols provided with the kit and were then analyzed using a flow cytometer $\left(\mathrm{MoFlo}^{\mathrm{TM}}\right.$ XDP; Beckman Coulter, Brea, CA, USA).

Statistical analysis. All statistical analyses were performed using SPSS 17.0 software. The differences between 2 groups were compared using the Student's t-test. Differences between nultiple groups were compared using one-way analysis of variance (ANOVA). Data are expressed as the means \pm standard deviation (SD). A p-value $<0.05$ was considered to indicate a statistically significant difference.

\section{Results}

Expression of HMGB1 in myocardial tissue and cardiomyocytes. In order to determine the role of the expression of HMGB1 in myocardial necrosis, the differential expression of HMGB1 in normal and myocardial tissue was detected. We found that the mRNA expression of HMGB1 was significantly increased at weeks 1 and 2 post-MI in the tissue with myocardial necrosis from the rats with $\mathrm{I} / \mathrm{R}$ injury when compared with the control 
heart tissue from the sham-operated rats $(\mathrm{p}<0.05$; Fig. $1 \mathrm{~A})$. In addition, a cell model of H/R injury using H9c2 cells was established, and we detected the expression of miR-210, which is a hypoxia-inducible factor and its overexpression is regarded as a biomarker for the successful induction of hypoxia (27-29). Our result revealed that the expression of miR-210 was significantly increased in the cells exposed to $H / R$ ( $p<0.05$; Fig. 1B), which indicated that the model of hypoxia was successfully established. In comparison to the control group, the mRNA expression of HMGB1 was increased during $\mathrm{H} / \mathrm{R}$ in the H9c2 cells $(\mathrm{p}<0.05$; Fig. 1B). Furthermore, we constructed a series of lentiviral vectors containing Lv-HMGB1-shRNA and Lv-HMGB1, and examined the efficiency of the silencing or the overexpression of HMGB1. We found that the mRNA and protein expression level of HMGB1 was decreased when the H9c2 cells were transfected with Lv-HMGB1-shRNA, while it was increased when the cells were transfected with Lv-HMGB1 ( $<<0.05$; Fig. 1C and D), suggesting that the lentiviral vectors containing Lv-HMGB1shRNA and Lv-HMGB1 were effectively transfected into the cells. In order to further examine the effects of $H / R$ on the expression of HMGB1, the mRNA and protein expression levels of HMGB1 were measured. The results revealed that the levels were decreased when the $\mathrm{H} 9 \mathrm{c} 2$ cells were transfected with Lv-HMGB1-shRNA during H/R, while they were increased when the cells were transfected with Lv-HMGB1 during H/R (p<0.05; Fig. 1E and F).

$H M G B 1$ induces apoptosis during H/R in cardiomyocytes. To determine the effects of HMGB1 on apoptosis during H/R in cardiomyocytes, we measured the expression levels of caspase-3 and $\mathrm{Bcl}-2$ (apoptosis-related proteins) in the cells. The results revealed that the protein expression level of cleaved caspase-3 was increased following $\mathrm{H} / \mathrm{R}$ in the $\mathrm{H} 9 \mathrm{c} 2$ cells, whereas the protein level of Bcl-2 was decreased ( $p<0.05$; Fig. 2A). The mRNA and protein level of cleaved caspase- 3 was downregulated when the H9c2 cells were transfected with Lv-HMGB1-shRNA during H/R, while it was upregulated when the cells were transfected with Lv-HMGB1 during H/R ( $<<0.05$; Fig. 2B and C). The mRNA and protein level of Bcl-2 was upregulated when the $\mathrm{H} 9 \mathrm{c} 2$ cells were transfected with Lv-HMGB1-shRNA during H/R, while it was downregulated when the cells were transfected with Lv-HMGB1 during H/R (p<0.05; (Fig. 2B and C). In addition, we examined whether HMGB1 induced apoptosis by flow cytometry. A decrease in the percentage of cells in early apoptosis (quadrant 2) plus late apoptosis (quadrant 3) was observed following transfection of the H9c2 cells with Lv-HMGB1-shRNA during H/R ( $<<0.05$; Fig. 2D and E). However, an increase in the percentage of cells in early apoptosis (quadrant 2) plus late apoptosis (quadrant 3) was observed following transfection of the H9c2 cells with Lv-HMGB1 during H/R (p<0.05; Fig. 2D and E). Furthermore, 3-MA, an autophagy inhibitor, markedly decreased the mRNA and protein expression levels of cleaved caspase-3, while it increased those of Bcl-2 during H/R in the H9c2 cells transfected with Lv-HMGB1 ( $<<0.05$; Fig. 2B and C). In addition, treatment with 3-MA decreased the percentage of apoptotic cells following transfection of the H9c2 cells with Lv-HMGB1 during H/R ( $<<0.05$; Fig. 2D and E). These results suggest that the induction of apoptosis by HMGB1 may be associated with autophagy during $\mathrm{H} / \mathrm{R}$ in cardiomyocytes.
HMGB1 promotes EMT in coordination with DDR1 during $H / R$ in cardiomyocytes. To determine the effects of HMGB1 on EMT during H/R in cardiomyocytes, the protein levels of the EMT biomakers, E-cadherin, vimentin and FSP, were detected by western blot analysis. In comparison to the Con $+\mathrm{H} / \mathrm{R}$ group, the protein level of the epithelial marker, E-cadherin, was upregulated when the $\mathrm{H} 9 \mathrm{c} 2$ cells were transfected with Lv-HMGB1-shRNA during H/R, while it was downregulated when the cells were transfected with Lv-HMGB1 during H/R ( $<<0.05$; Fig. 3). Compared to the Con $+\mathrm{H} / \mathrm{R}$ group, the protein levels of the mesenchymal markers, vimentin and FSP, were downregulated when the H9c2 cells were transfected with Lv-HMGB1-shRNA during H/R. However, the levels of these markers were upregulated when the cells were transfected with Lv-HMGB1 during H/R (p<0.05; Fig. 3).

Furthermore, in comparison to the Lv-HMGB1-shRNA group, the protein level of the epithelial marker, E-cadherin, was decreased when the $\mathrm{H} 9 \mathrm{c} 2$ cells were transfected with Lv-HMGB1 during H/R. However, compared to the Lv-HMGB1 +H/R group, the level was increased when the cells were transfected with both Lv-HMGB1-shRNA and DDR1 TALEN during H/R ( $<<0.05$; Fig. 3). Compared to the Lv-HMGB1-shRNA group, the protein levels of the mesenchymal markers, vimentin and FSP, were increased when the cells were transfected with Lv-HMGB1 during H/R. However, compared to the Lv-HMGB1 +H/R group, the levels were decreased when the $\mathrm{H} 9 \mathrm{c} 2$ cells were transfected with Lv-HMGB1 and DDR1 TALEN during H/R (p<0.05; Fig. 3).

$H / R$ induces autophagy in cardiomyocytes. The H9c2 cells were subjected to $H / R$, and the protein expression levels of Beclin 1, LC3-II/LC3-I and p62, markers of autophagy, were then examined by western blot analysis. The results revealed that the levels of Beclin 1 and the ratio of LC3-II/LC3-I were increased, whereas the expression of p62 was decreased in the $\mathrm{H} 9 \mathrm{c} 2$ cells following $\mathrm{H} / \mathrm{R}$, suggesting that $\mathrm{H} / \mathrm{R}$ induces autophagy in H9c2 cells ( $\mathrm{p}<0.05$; Fig. 4A).

HMGB1 mediates autophagy following $H / R$ injury in cardiomyocytes. In this study, we also examined the effects of HMGB1 on H9c2 cell autophagy following H/R. We found that the protein levels of Beclin 1 and LC3-II/I were decreased when the cells were transfected with Lv-HMGB1-shRNA, whereas these levels were increased when the $\mathrm{H} 9 \mathrm{c} 2$ cells were transfected with Lv-HMGB1 during H/R ( $<<0.05$; Fig. 4B). Moreover, the content of Beclin 1 during $\mathrm{H} / \mathrm{R}$ in the $\mathrm{H} 9 \mathrm{c} 2$ cells was also determined by performing ICC. The results revealed that the content of Beclin 1 was decreased when the cells were transfected with Lv-HMGB1-shRNA, whereas it was increased when the H9c2 cells were transfected with Lv-HMGB1 during H/R. The Beclin 1 content was also decreased following treatment of the cells with 3-MA (an autophagy inhibitor) ( $\mathrm{p}<0.05$; Fig. 4C).

HMGB1 induces autophagy through the upregulation of the expression of DDRl and the downregulation of the phosphorylation of $m T O R$. In order to further explore the mechanisms of action of HMGB1 and its effects on autophagy during H/R in cardiomyocytes, the expression of DDR1 in myocardial tissue from rats with H/R injury and in H9c2 cells subjected 
A

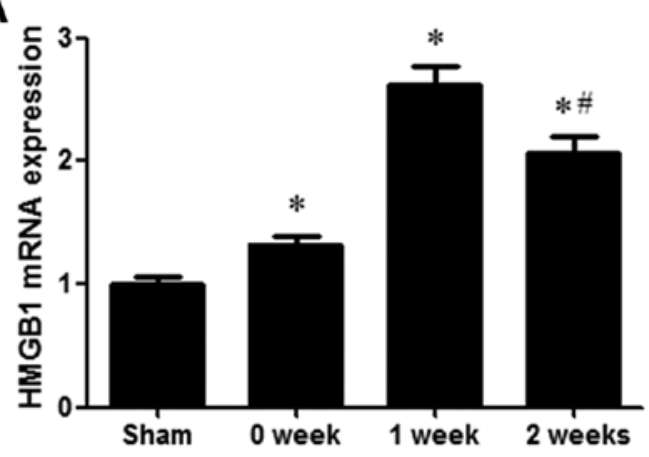

C

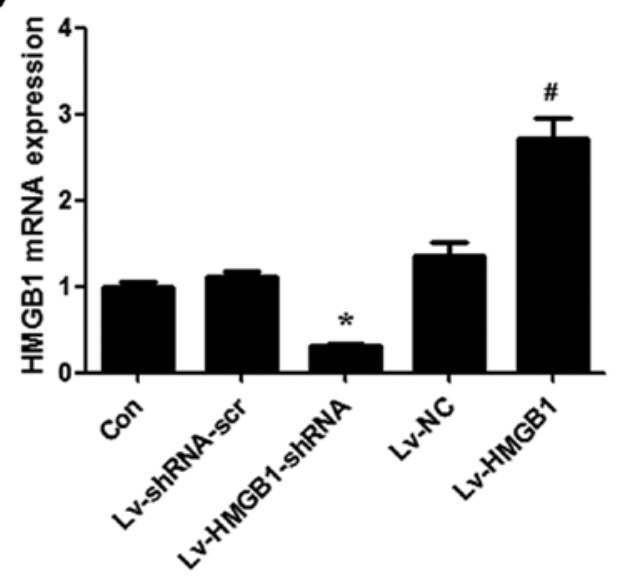

D
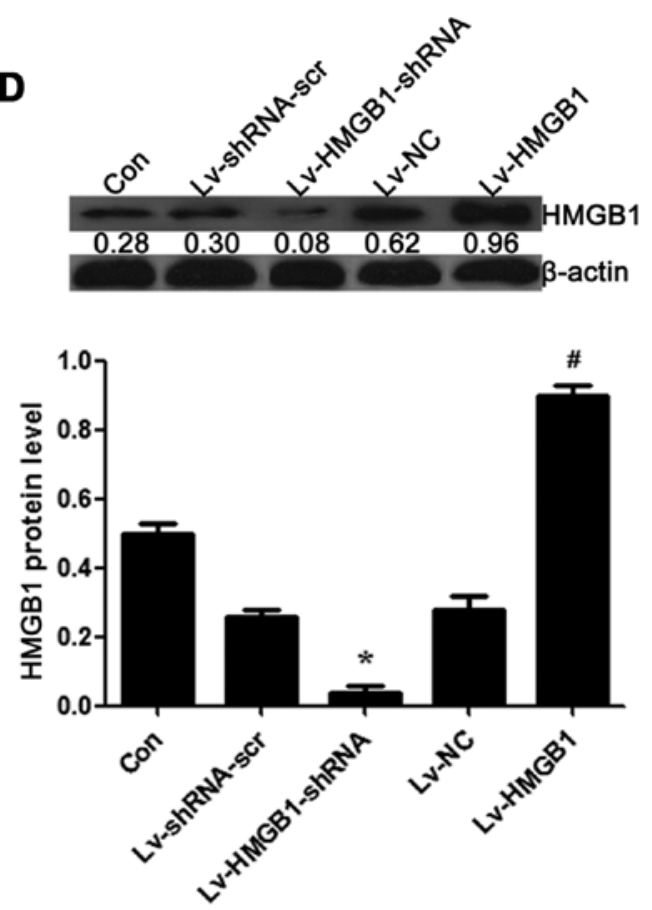

B

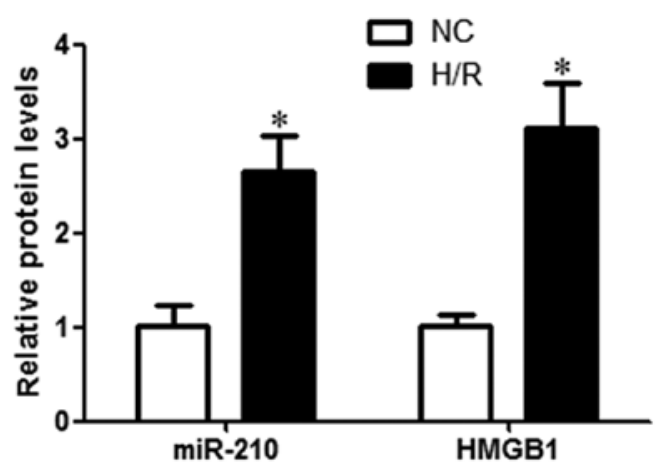

$\mathbf{E}$

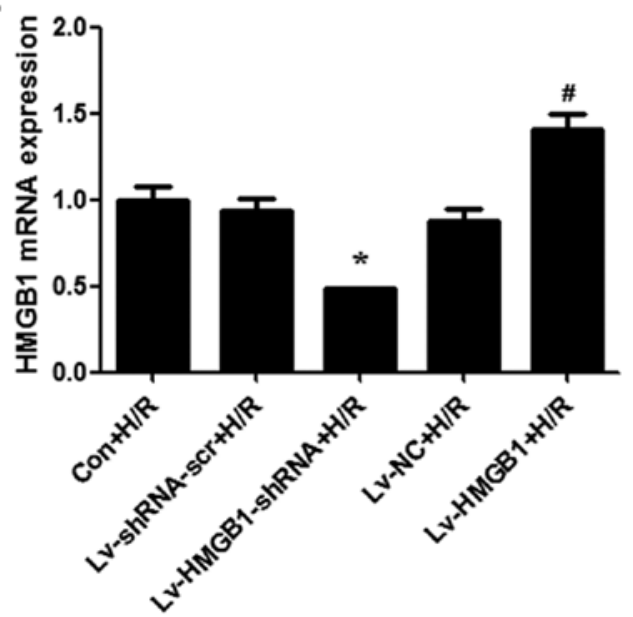

$\mathbf{F}$
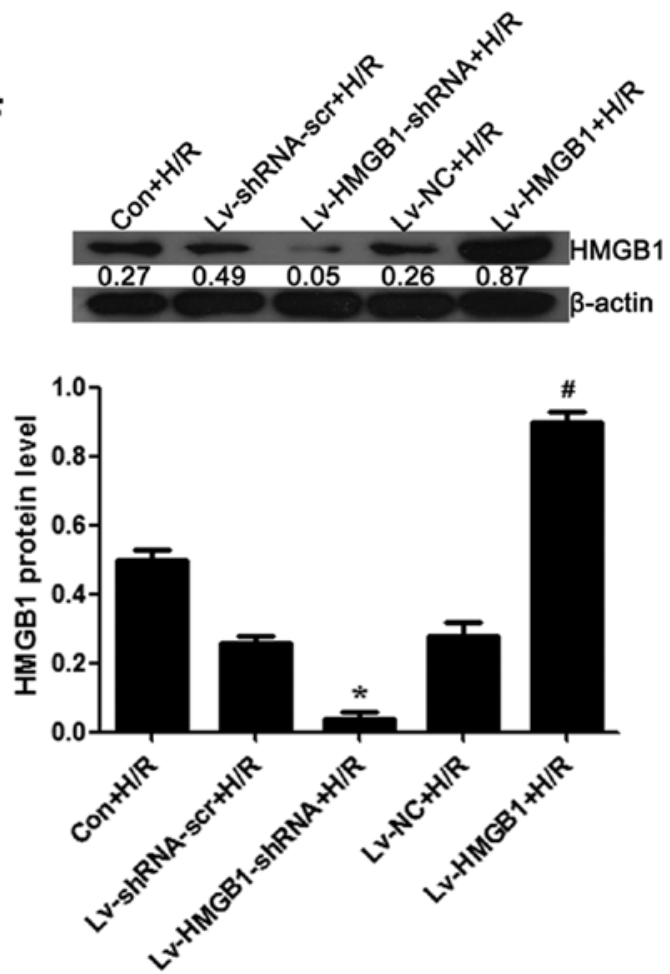

Figure 1. Expression of high mobility group box 1 (HMGB1) in myocardial tissue and cardiomyocytes. (A) The mRNA expression of HMGB1 in the area of myocardial necrosis in rats subjected to hypoxia/reoxygenation (H/R). (B) The mRNA expression of the H/R biomarker, miR-210, and HMGB1 during H/R in cardiomyocytes. (C) HMGB1 mRNA expression in cardiomyocytes transfected with a lentiviral vector carrying HMGB1-shRNA or an HMGB1 overexpression vector. (D) HMGB1 protein level in cardiomyocytes transfected with a lentiviral vector carrying HMGB1-shRNA or an HMGB1 overexpression vector. (E) HMGB1 mRNA expression during H/R in cardiomyocytes transfected with a lentiviral vector carrying HMGB1-shRNA or an HMGB1 overexpression vector. (F) HMGB1 protein level during $\mathrm{H} / \mathrm{R}$ in cardiomyocytes transfected with a lentiviral carrying HMGB1-shRNA or an HMGB1 overexpression vector. Data are expressed as the means \pm SD. $n=8$ or 3 samples/group; ${ }^{*} \mathrm{p}<0.05$ vs. control (Con; untransfected cells); ${ }^{\#} \mathrm{p}<0.05$ vs. cells at 1 week or cells transfected with the negative control HMGB1 ( Lv + NC), or with Lv-NC + H/R. 
A

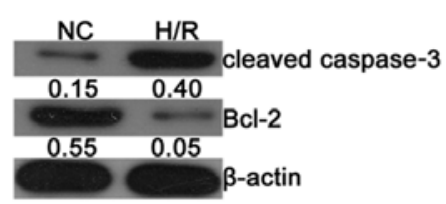

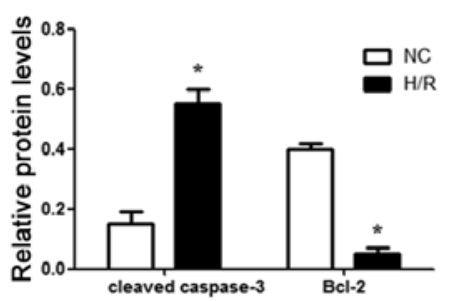

C

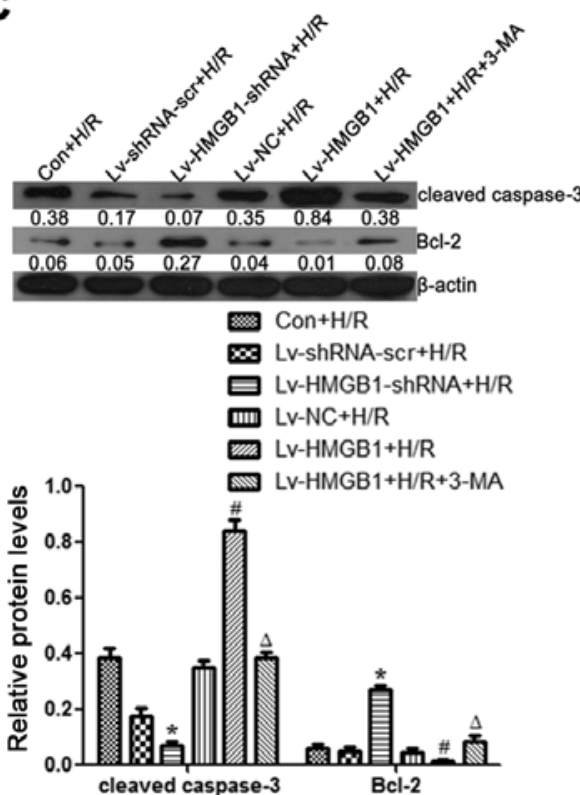

B

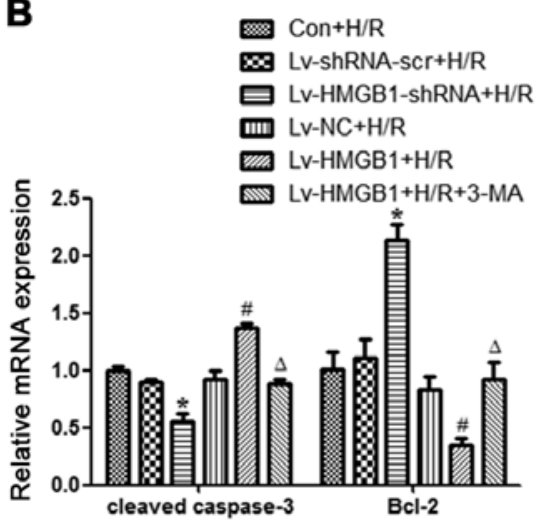

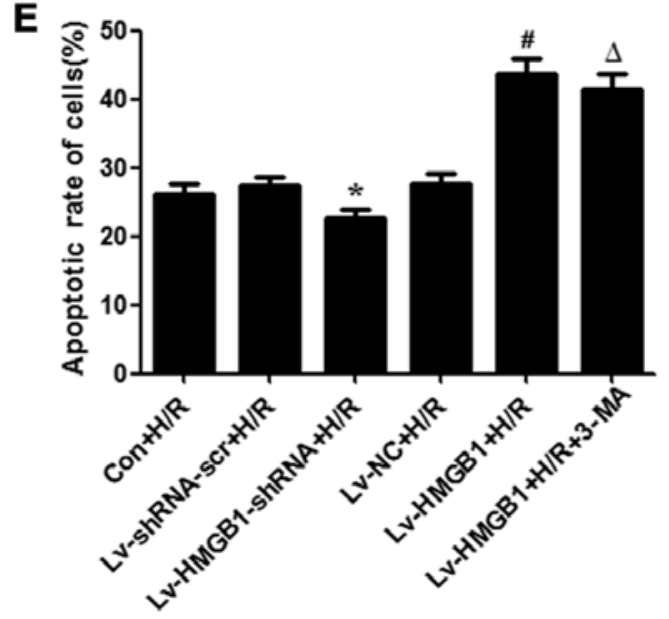

D
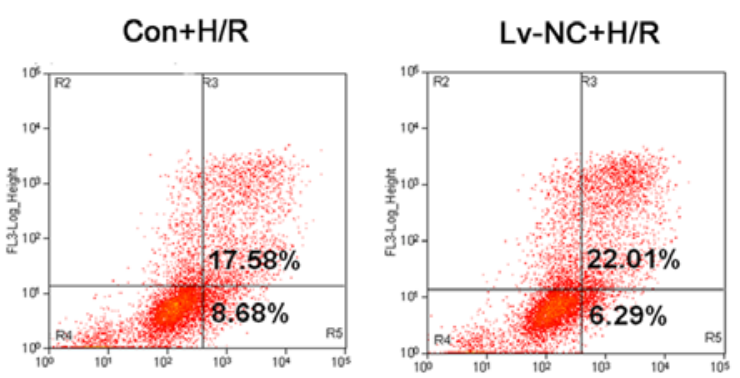

Lv-HMGB1-shRNA+H/R

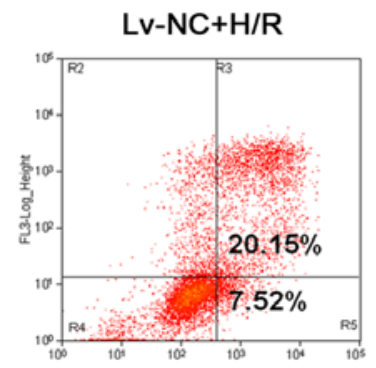

Lv-HMGB1+H/R

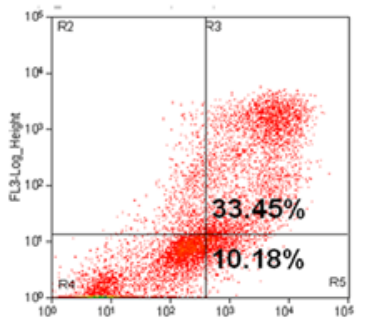

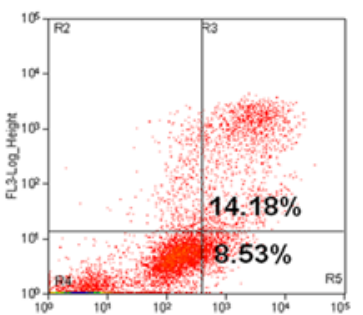

Lv-HMGB1+H/R+3-MA

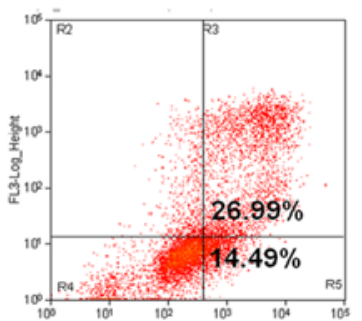

Figure 2. High mobility group box 1 (HMGB1) induces apoptosis during hypoxia/reoxygenation (H/R) in cardiomyocytes. (A) The protein expression of the apoptosis-related proteins, caspase-3 and Bcl-2. (B) The mRNA expression of apoptosis-related caspase-3 and Bcl-2 during $\mathrm{H} / \mathrm{R}$ in cardiomyocytes transfected with a lentiviral vector carrying HMGB1-shRNA or with an HMGB1 overexpression vector. (C) The protein level of apoptosis-related caspase-3 and Bcl-2 during $\mathrm{H} / \mathrm{R}$ in cardiomyocytes transfected with a lentiviral vector carrying HMGB1-shRNA or with an HMGB1 overexpression vector. (D) HMGB1 induces the apoptosis of cardiomyocytes in vitro. Flow cytometric analyses of Annexin V/propidium iodide (PI) staining of H9c2 cells. (E) The percentages of cells in early apoptosis (quadrant 2) plus late apoptosis (quadrant 3) were identified following $\mathrm{H} / \mathrm{R}$ in cardiomyocytes. Data are expressed as means $\pm \mathrm{SD}$. $\mathrm{n}=3$ samples/group; ${ }^{*} \mathrm{p}<0.05 \mathrm{vs}$. negative control (NC), control (Con) + H/R, or Lv-shRNA-scr + H/R; " ${ }^{p}<0.05$ vs. Lv-NC (negative control) + H/R; ${ }^{\wedge} \mathrm{p}<0.05$ vs. Lv-HMGB1 + H/R.
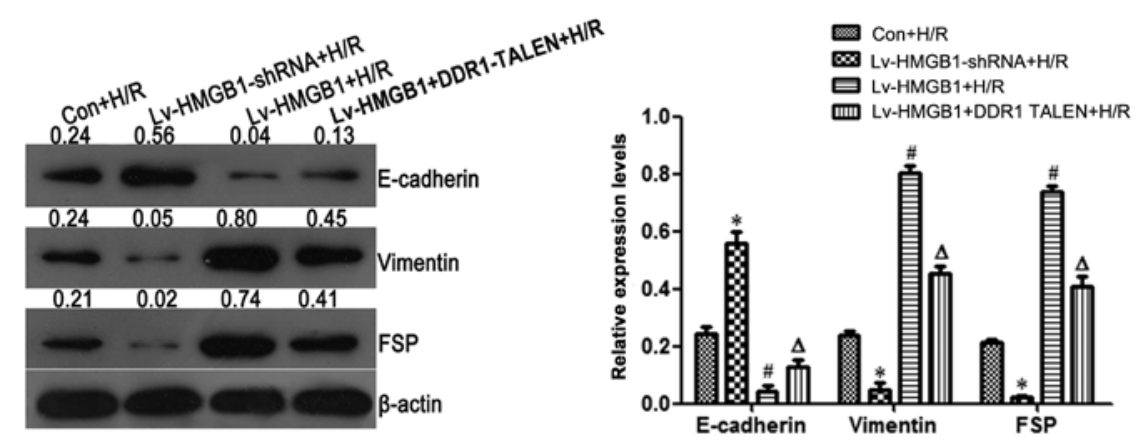

Figure 3. High mobility group box 1 (HMGB1) induces epithelial-to-mesenchymal transition following hypoxia/reoxygenation (H/R) in cardiomyocytes. The protein levels of EMT biomakers [E-cadherin, vimentin and fibroblast-specific protein (FSP)] during H/R in cardiomyocytes transfected with a lentiviral vector carrying HMGB1-shRNA or with an HMGB1 overexpression vector, or with the HMGB1 overexpression vector and discoidin domain receptor 1 (DDR1) TALEN. Data are expressed as the means \pm SD. $n=3$ samples/group; ${ }^{* * \#} \mathrm{p}<0.05$ vs. control (Con) $+\mathrm{H} / \mathrm{R} ;{ }^{\wedge} \mathrm{p}<0.05$ vs. Lv-HMGB1 + H/R. 
A

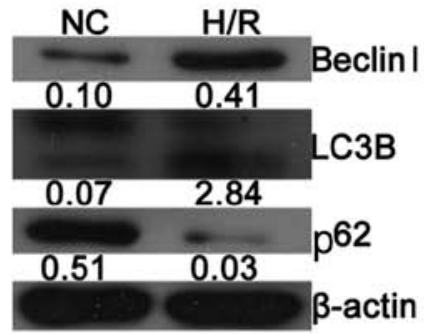

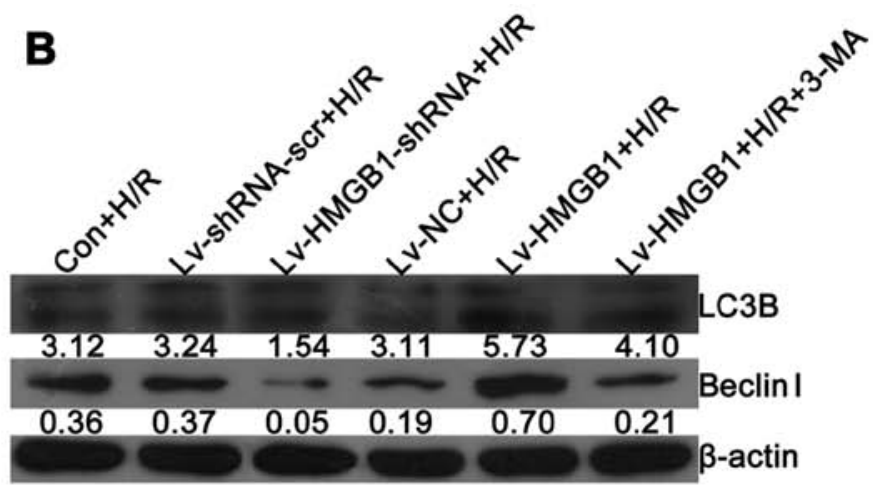

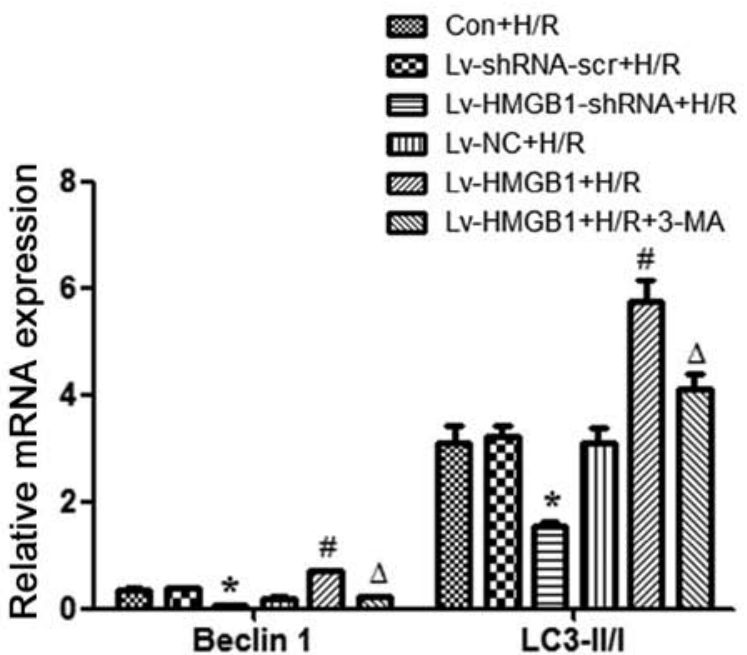

C

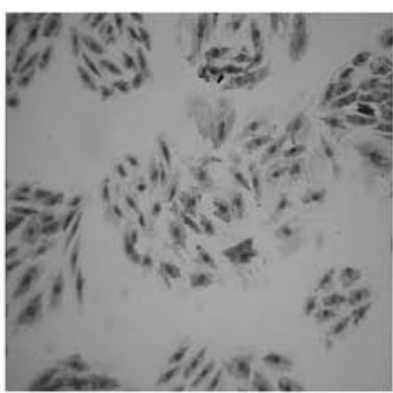

Con+H/R

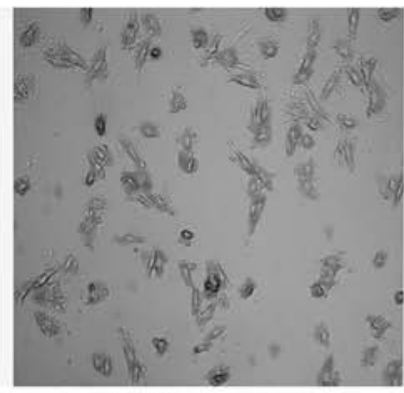

Lv-HMGB1-shRNA+H/R

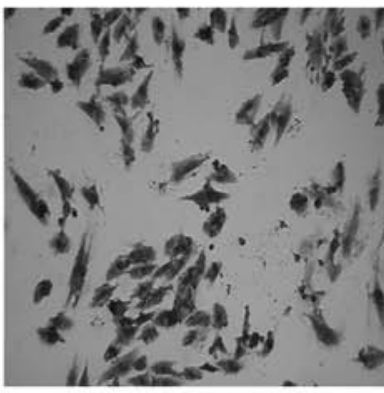

Lv-HMGB1+H/R

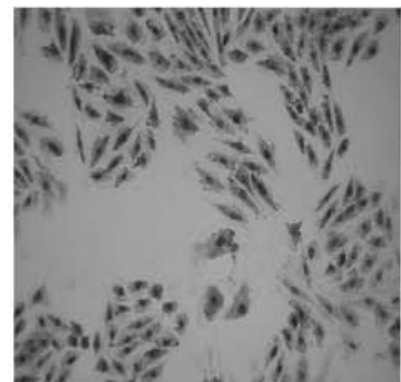

Lv-HMGB1+H/R+3-MA

Figure 4. High mobility group box 1 (HMGB1) regulates autophagy following hypoxia/reoxygenation (H/R) in cardiomyocytes. (A) The protein levels of autophagy biomakers (Beclin 1, LC3-II/I and p62). (B) The protein level of Beclin 1 and LC3-II/I during H/R in cardiomyocytes transfected with a lentiviral vector carrying HMGB1-shRNA or with an HMGB1 overexpression vector. (C) The content of Beclin 1 during H/R in cardiomyocytes transfected with a lentiviral vector carrying HMGB1-shRNA or with an HMGB1 overexpression vector. Data are expressed as the means \pm SD. n=3 samples/group, ${ }^{*}$ p $<0.05$ vs. NC (negative control) or control (Con) + H/R; ${ }^{\#} \mathrm{p}<0.05$ vs. Lv-NC + H/R; ${ }^{\wedge} \mathrm{p}<0.05$ vs. Lv-HMGB1 + H/R.

to H/R injury was determined by RT-qPCR and western blot analysis. The results revealed that the mRNA expression of DDR1 was significantly increased at weeks 1 and 2 post-MI in the tissue with myocardial necrosis from the rats with $\mathrm{I} / \mathrm{R}$ injury when compared with the control heart tissue from the sham-operated rats ( $<<0.05$; Fig. 5A). Compared to the control group, the mRNA expression of DDR1 was increased during $\mathrm{H} / \mathrm{R}$ in the H9c2 cells ( $\mathrm{p}<0.05$; Fig. 5B). For further investigations on the regulatory effects of HMGB1 on the expression of DDR1 during H/R in cardiomyocytes, the mRNA and protein levels of DDR1 were measured following transfection of the H9c2 cells with either Lv-HMGB1-shRNA or Lv-HMGB1. The results revealed that DDR1 expression was decreased when the H9c2 cells were transfected with Lv-HMGB1-shRNA during $\mathrm{H} / \mathrm{R}$, whereas it was increased when the cells were transfected with Lv-HMGB1 during H/R ( $<<0.05$; Fig. 5C and D).

We also examined the effects of HMGB1 on the expression and phosphorylation of mTOR. The results revealed that OSI-027, an inhibitor of mTOR, decreased the phosphorylation level of mTOR $(\mathrm{p}<0.05)$, but had no effect on the protein level of mTOR when the cells were transfected with Lv-HMGB1 ( $p>0.05$; Fig. 6). The protein level of Beclin 1 was also decreased, while the expression level of p62 was increased when the H9c2 cells were treated with OSI-027 and transfected with Lv-HMGB1. 

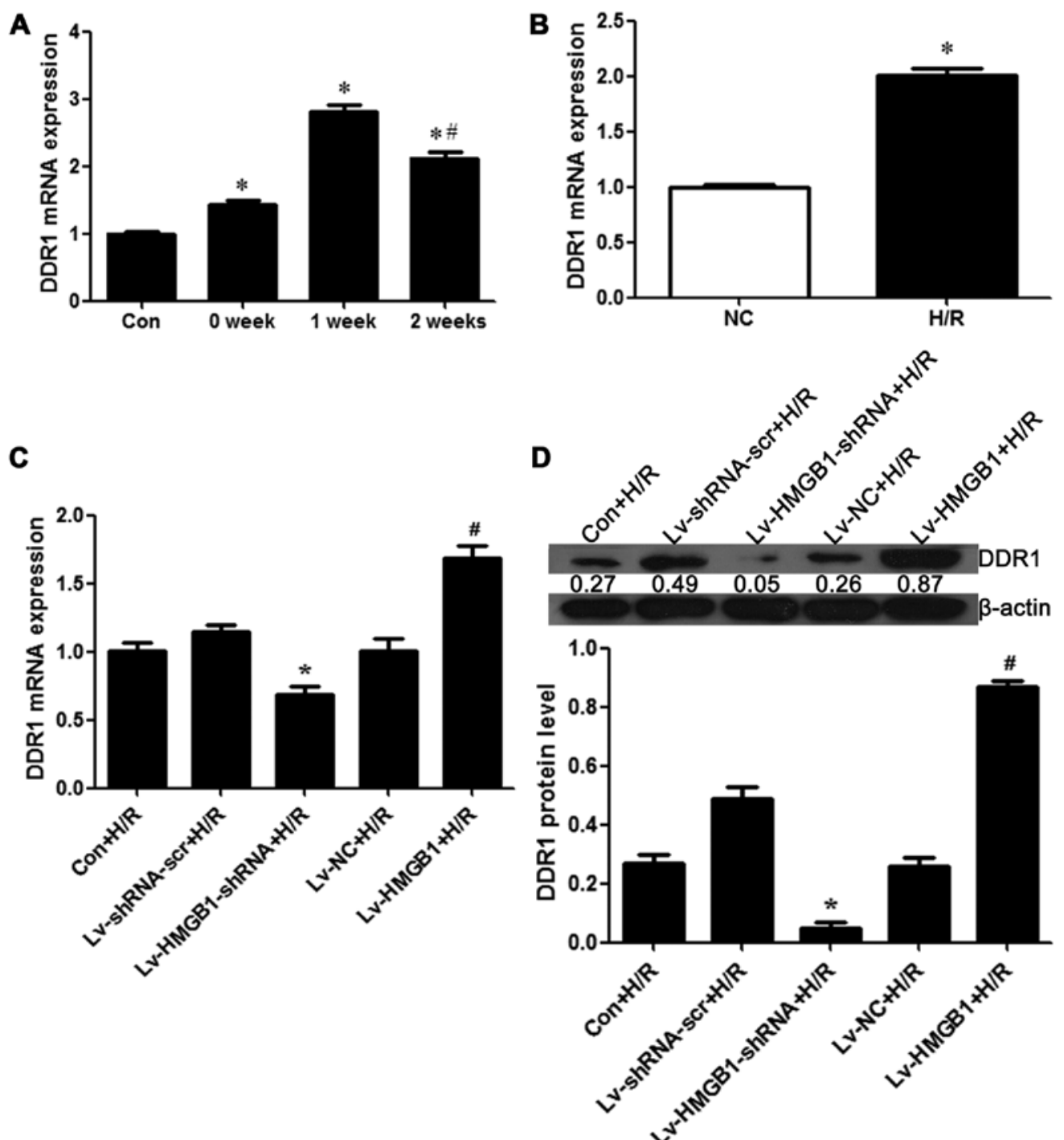

Figure 5. High mobility group box 1 (HMGB1) induces autophagy by upregulating the expression of discoidin domain receptor 1 (DDR1). (A) The mRNA expression of DDR1 in the area of myocardial necrosis of rats subjected to hypoxia/reoxygenation (H/R). (B) The mRNA expression of DDR1 during H/R in cardiomyocytes. (C) DDR1 mRNA expression during H/R in cardiomyocytes transfected with a lentiviral carrying HMGB1-shRNA or with an HMGB1 overexpression vector (D) DDR1 protein level during H/R in cardiomyocytes transfected with a lentiviral carrying HMGB1-shRNA or with an HMGB1 overexpression vector.. Data are expressed as the means $\pm \mathrm{SD}$. $\mathrm{n}=3$ samples/group, ${ }^{*} \mathrm{p}<0.05$ vs. control (Con) or NC (negative control) $+\mathrm{H} / \mathrm{R}$ or Lv-shRNA-scr $+\mathrm{H} / \mathrm{R}$; $" \mathrm{p}<0.05 \mathrm{vs}$. Lv-NC $+\mathrm{H} / \mathrm{R}$.
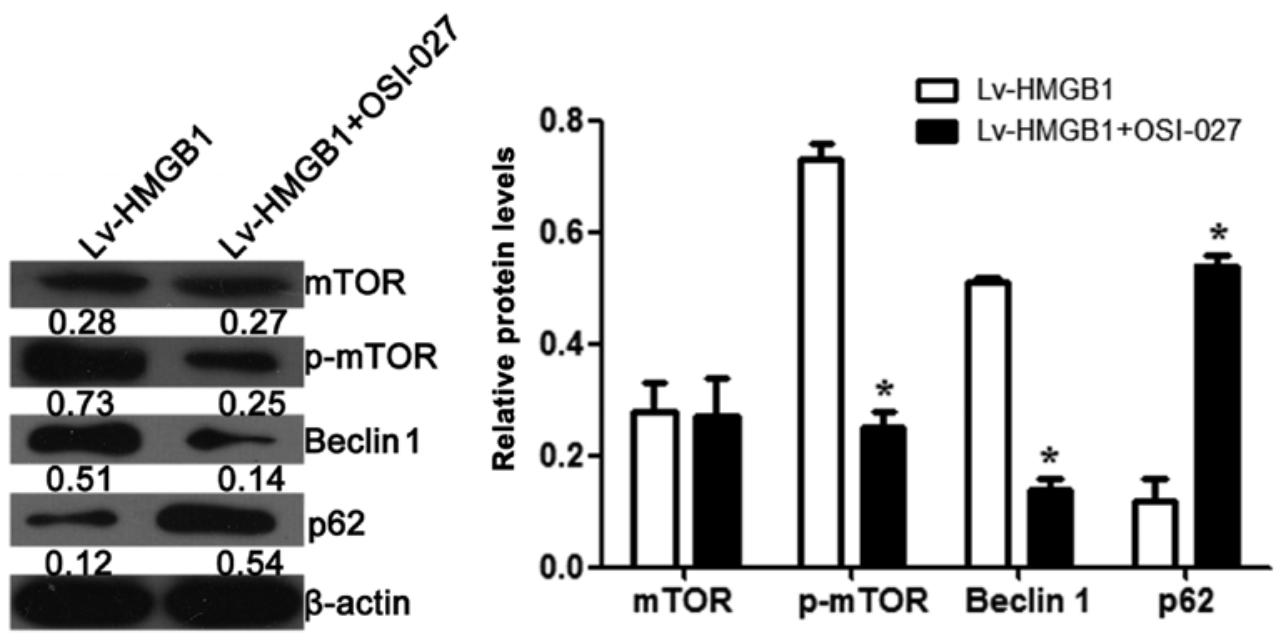

Figure 6. High mobility group box 1 (HMGB1) induces autophagy by downregulating the phosphorylation of mammalian target of rapamycin (mTOR). The protein and phosphorylation level of mTOR in cardiomyocytes following treatment with OSI-027; the protein levels of Beclin 1 and p62 in cardiomyocytes following treatment with OSI-027. Data are expressed as the means \pm SD. $n=3$ samples/group, ${ }^{p}<<0.05$ vs. Lv-HMGB1. 


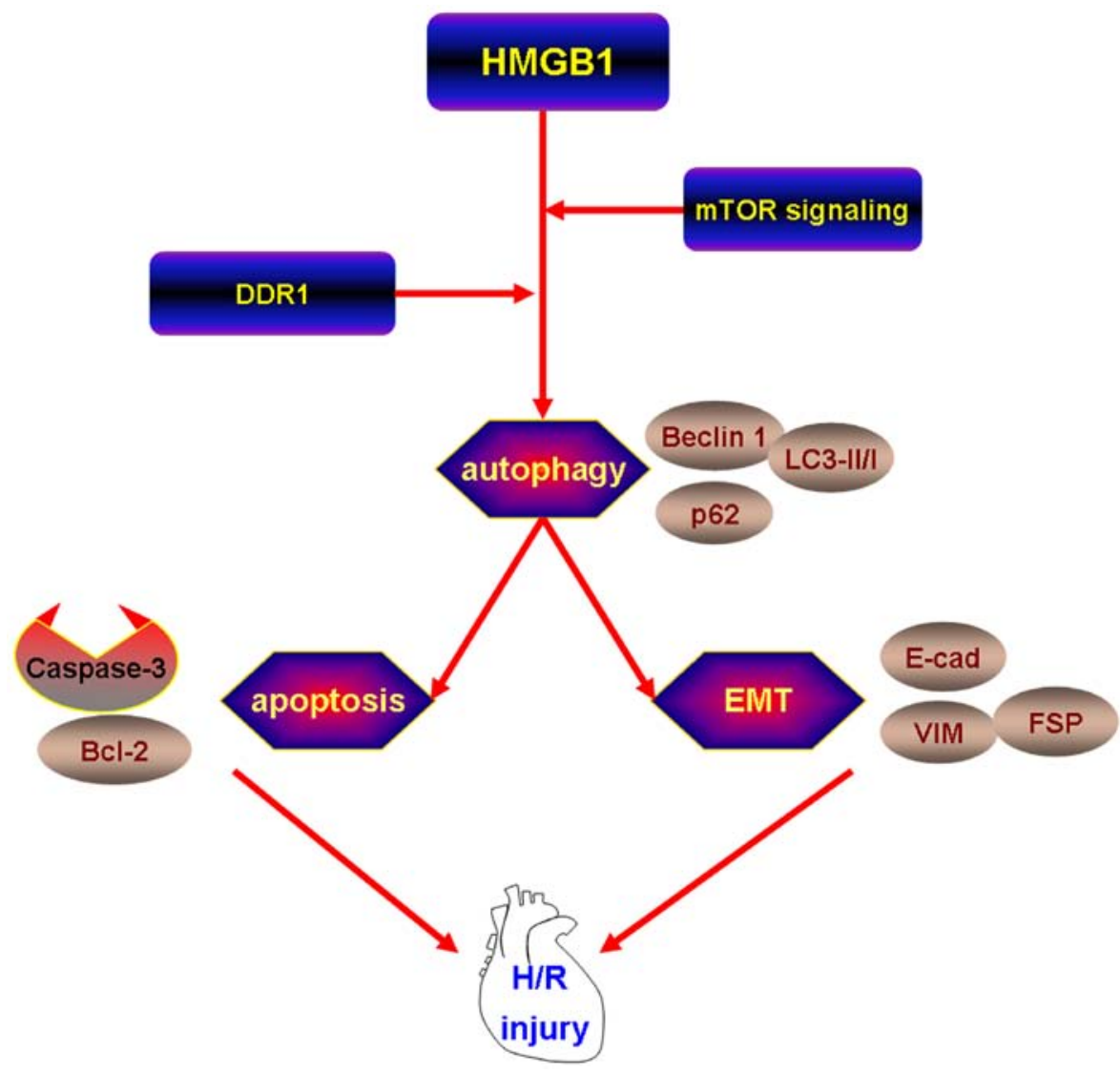

Figure 7. Schematic diagram of the functions of high mobility group box 1 (HMGB1) during hypoxia/reoxygenation (H/R) injury in cardiomyocytes. HMGB1 promoted apoptosis and epithelial-to-mesenchymal transition (EMT) by inducing autophagy through the upregulation of the expression of discoidin domain receptor 1 (DDR1) and the downregulation of the phosphorylation of mammalian target of rapamycin (mTOR following H/R injury in cardiomyocytes. VIM, vimentin; FSP, fibroblast-specific protein.

\section{Discussion}

H/R injury occurs in a number of of important clinical conditions, such as MI (30). Severe hypoxia threatens the viability of the myocardium and, ultimately, cardiac function. Subsequent reoxygenation may subject cells to further damage (31). H/R injury is a complex, multifactorial pathophysiological process, which mainly involves the actions of nitric oxide (NO) (32-34), reactive oxygen species (ROS) production $(35,36)$, and other molecules, such as HMGB1 $(22,37)$. In this study, we found that HMGB1 was upregulated in the tissues of rats with MI and in H9c2 cells following H/R injury.

As a protein considered to be representative of damageassociated molecular patterns (38), HMGB1 is actively secreted by immune cells and some non-immune cells or is passively released by necrotic cells (39). HMGB1 is a multifunctional, ubiquitous protein located inside and outside cells that plays a critical role in various physiological and pathological processes, including cell development, differentiation, inflammation, immunity, metastasis, metabolism and death (40). However, to the best of our knowledge, there are no studies available to date on the effects of HMGB1 on EMT in cardiomyocytes. EMT is a biological process that is involved in tissue fibrosis and cancer metastasis. Recent research has indicated that EMT is re-activated in the heart following ischemic injury (41). E-cadherin commonly serves as an epithelial marker, while vimentin and FSP as mesenchymal markers (42-44). Thus, in this study, we observed the biological roles of HMGB1 in apoptosis and those of EMT markers in H/R injury to H9c2 cells, and found that HMGB1 induced apoptosis by increasing the mRNA and protein expression of cleaved caspase- 3 and the apoptotic rate of the cells, while decreasing the expression of $\mathrm{Bcl}-2$, and promoting EMT. It also decreased the protein level of the epithelial marker, E-cadherin, and increased the protein expression of the mesenchymal markers, vimentin and FSP, during $\mathrm{H} / \mathrm{R}$ in the $\mathrm{H} 9 \mathrm{c} 2$ cells.

Autophagy is a highly evolutionarily conserved cellular process through which long-lived proteins and damaged organelles are recycled to maintain cellular homeostasis (45). These proteins and organelles are sequestered into autophagosomes and are then delivered to lysosomes for degradation (46). As a major intracellular degradation and recycling pathway, autophagy is crucial for maintaining homeostasis, as well as remodeling during normal development, and dysfunctions in autophagy have been shown to be associated with a variety of pathologies, including cancers, inflammatory diseases and MI (47). Beclin 1, LC3-II/I and p62 are usually considered as markers of autophagy. The results of our present study demonstrated that the expression of Beclin 1 and LC3-II/I was markedly increased, while that of p62 was decreased during $H / R$ injury, thus indicating that $H / R$ injury induces autophagy in cardiomyocytes. As an important mediator of systemic autophagic syndrome, HMGB1 participates in the autophagy process at several levels, including at the nuclear, cytosolic 
and extracellular level (40). HMGB1-induced autophagy plays a vital role in various diseases, such as cancer (48-51), endotoxemia/bacterial infection $(52,53)$, diabetes mellitus (54); however, research on the role of HMGB1-induced autophagy in $\mathrm{H} / \mathrm{R}$ injury or MI is limited (22). Thus, we found that through autophagy that HMGB1 promoted apoptosis and EMT during $\mathrm{H} / \mathrm{R}$ injury in cardiomyocytes.

It has been reported that the expression of DDR1 is increased in the MI-affected area of rats with congestive heart failure (55). It is thus worth researching whether DDR1 is involved in H/R injury in MI. DDR-1 is a receptor tyrosine kinase (RTK). In humans, the DDR-1 gene is localized on chromosome 6 , in the region $6 \mathrm{p} 21.3(56,57)$. DDR1 is uniquely positioned to function as a sensor for the extracellular matrix and to regulate a wide range of cellular functions from migration and proliferation to cytokine secretion and extracellular matrix homeostasis/remodeling (58). While the activation of DDR1 by extracellular matrix collagens is required for normal development and tissue homeostasis, the aberrant activation of these receptors following injury or in disease is detrimental, and has been implicated in several diseases, such as fibrosis, atherosclerosis and cancer (59). However, to the best of our knowledge, there are no available studies to date on the association between DDR1 and H/R injury in MI. Thus, in the present study, we examined whether DDR1 is involved in $\mathrm{H} / \mathrm{R}$ injury, and found that the expression of DDR1 was significantly elevated in tissues of rats with $\mathrm{MI}$ and in cardiomyocytes following $H / R$ injury. We then examined the role of DDR1 in HMGB1-induced autophagy following H/R injury in cardiomyocytes, and found that HMGB1 induced autophagy by upregulating the expression of DDR1.

In order to further explore the mechanisms of action of HMGB1 in apoptosis and EMT in H/R injury, we examined the alteration of autopagy-related signaling, mTOR following treatment with its inhibitor, OSI-027. The results revealed that OSI-027 decreased the protein level of Beclin 1, and increased the level of p62. It did not alter the protein level of mTOR, but altered its phosphorylation level in $\mathrm{H} 9 \mathrm{c} 2$ cells following transfection with an HMGB1 overexpression vector (Lv-HMGB1). This suggests that HMGB1 induces autophagy by downregulating the phosphorylation of mTOR.

In conclusion, the findings of our study demonstrated the following: i) the expression of HMGB1 was upregulated in the myocardial tissue of rats with $\mathrm{MI}$ and following $\mathrm{H} / \mathrm{R}$ injury to H9c2 cells; ii) HMGB1 promoted apoptosis and EMT during $\mathrm{H} / \mathrm{R}$ in $\mathrm{H} 9 \mathrm{c} 2$ cells; iii) in association with the induction of autophagy, HMGB1 induces apoptosis and EMT following H/R in H9c2 cells; iv) HMGB1 induced autophagy by upregulating the expression of DDR1 and downregulating the phosphorylation of mTOR (Fig. 7). Thus, it can be concluded that HMGB1 promotes apoptosis and EMT in association with the induction of autophagy through the upregulation of the expression of DDR1 and the downregulation of the phosphorylation of mTOR following H/R injury in cardiomyocytes.

\section{References}

1. Aydin S, Kuloglu T, Aydin S, Kalayci M, Yilmaz M, Çakmak T and Eren MN: Elevated adropin: A candidate diagnostic marker for myocardial infarction in conjunction with troponin-I. Peptides 58: 91-97, 2014.
2. Cabello JB, Burls A, Emparanza JI, Bayliss S and Quinn T: Oxygen therapy for acute myocardial infarction. Cochrane Database Syst Rev 8: CD007160, 2013.

3. Anderson JL, Adams CD, Antman EM, Bridges CR, Califf RM, Casey DE Jr, Chavey WE II, Fesmire FM, Hochman JS, Levin TN, et al; American College of Cardiology Foundation/American Heart Association Task Force on Practice Guidelines: 2012 ACCF/ AHA focused update incorporated into the ACCF/AHA 2007 guidelines for the management of patients with unstable angina/ non-ST-elevation myocardial infarction: A report of the American College of Cardiology Foundation/American Heart Association Task Force on Practice Guidelines. Circulation 127: e663-e828, 2013.

4. Brown HF: Synopsis and Review of the American College of Cardiology Foundation/American Heart Association 2013 ST-Elevation Myocardial Infarction Guideline. AACN Adv Crit Care 25: 142-150, 2014.

5. Mitra A,Ray A,Datta R,Sengupta S and Sarkar S: Cardioprotective role of p38 MAPK during myocardial infarction via parallel activation of $\alpha$-crystallin B and Nrf2. J Cell Physiol 229: 1272-1282, 2014.

6. Sahoo S and Losordo DW: Exosomes and cardiac repair after myocardial infarction. Circ Res 114: 333-344, 2014.

7. Gai Y, Ma Z, Yu X, Qu S and Sui D: Effect of ginsenoside Rh1 on myocardial injury and heart function in isoproterenol-induced cardiotoxicity in rats. Toxicol Mech Methods 22: 584-591, 2012.

8. Go AS, Mozaffarian D, Roger VL, Benjamin EJ, Berry JD, Borden WB, Bravata DM, Dai S, Ford ES, Fox CS, et al; American Heart Association Statistics Committee and Stroke Statistics Subcommittee: Heart disease and stroke statistics - 2013 update: A report from the American Heart Association. Circulation 127: e6-e245, 2013.

9. Cao X, Chen A, Yang P, Song X, Liu Y, Li Z, Wang X, Wang L and Li Y: Alpha-lipoic acid protects cardiomyocytes against hypoxia/reoxygenation injury by inhibiting autophagy. Biochem Biophys Res Commun 441: 935-940, 2013.

10. Verma S, Fedak PW, Weisel RD, Butany J, Rao V, Maitland A, Li RK, Dhillon B and Yau TM: Fundamentals of reperfusion injury for the clinical cardiologist. Circulation 105: 2332-2336, 2002.

11. Feng Y, Hu L, Xu Q, Yuan H, Ba L, He Y and Che H: Cytoprotective role of alpha1-antitrypsin in vascular endothelial cell under hypoxia/reoxygenation condition. J Cardiovasc Pharmacol 66: 96-107, 2015.

12. Cao X, Wang X, Ling Y, Song X, Yang P, Liu Y, Liu L, Wang L, Guo J and Chen A: Comparison of the degree of autophagy in neonatal rat cardiomyocytes and $\mathrm{H} 9 \mathrm{c} 2$ cells exposed to hypoxia/ reoxygenation. Clin Lab 60: 809-814, 2014.

13. Zhang Y, Hu S and Chen Y: Hepatocyte growth factor suppresses hypoxia/reoxygenation-induced $\mathrm{XO}$ activation in cardiac microvascular endothelial cells. Heart Vessels, 2014.

14. Hock R, Furusawa T, Ueda T and Bustin M: HMG chromosomal proteins in development and disease. Trends Cell Biol 17: 72-79, 2007.

15. Zhao X, Kuja-Panula J, Rouhiainen A, Chen YC, Panula P and Rauvala H: High mobility group box-1 (HMGB1; amphoterin) is required for zebrafish brain development. J Biol Chem 286: 23200-23213, 2011.

16. Rauvala $\mathrm{H}$ and Rouhiainen A: Physiological and pathophysiological outcomes of the interactions of HMGB1 with cell surface receptors. Biochim Biophys Acta 1799: 164-170, 2010.

17. Stros M: HMGB proteins: Interactions with DNA and chromatin. Biochim Biophys Acta 1799: 101-113, 2010.

18. Zhou X, Hu X, Xie J, Xu C, Xu W and Jiang H: Exogenous highmobility group box 1 protein injection improves cardiac function after myocardial infarction: Involvement of Wnt signaling activation. J Biomed Biotechnol 2012: 743879, 2012.

19. Nakamura Y, Suzuki S, Shimizu T, Miyata M, Shishido T, Ikeda K, Saitoh S, Kubota I and Takeishi Y: High mobility group box 1 promotes angiogenesis from bone marrow-derived endothelial progenitor cells after myocardial infarction. $\mathrm{J}$ Atheroscler Thromb 22: 570-581, 2015.

20. He YY, Wen Y, Zheng XX and Jiang XJ: Intramyocardial delivery of HMGB1 by a novel thermosensitive hydrogel attenuates cardiac remodeling and improves cardiac function after myocardial infarction. J Cardiovase Pharmacol 61: 283-290, 2013.

21. Andrassy M, Volz HC, Riedle N, Gitsioudis G, Seidel C, Laohachewin D, Zankl AR, Kaya Z, Bierhaus A, Giannitsis E, et al: HMGB1 as a predictor of infarct transmurality and functional recovery in patients with myocardial infarction. J Intern Med 270: 245-253, 2011. 
22. Xu W, Jiang $\mathrm{H}, \mathrm{Hu} X$ and $\mathrm{Fu} \mathrm{W}$ : Effects of high-mobility group box 1 on the expression of Beclin-1 and LC3 proteins following hypoxia and reoxygenation injury in rat cardiomyocytes. Int $\mathbf{J}$ Clin Exp Med 7: 5353-5357, 2014

23. Tang D, Kang R, Livesey KM, Cheh CW, Farkas A, Loughran P, Hoppe G, Bianchi ME, Tracey KJ, Zeh HJ III, et al: Endogenous HMGB1 regulates autophagy. J Cell Biol 190: 881-892, 2010

24. Kang R, Livesey KM, Zeh HJ III, Lotze MT and Tang D: HMGB1 as an autophagy sensor in oxidative stress. Autophagy 7: 904-906, 2011.

25. Ma S, Wang Y, Chen Y and Cao F: The role of the autophagy in myocardial ischemia/reperfusion injury. Biochim Biophys Acta 1852: 271-276, 2015

26. Sciarretta S, Hariharan N, Monden Y,Zablocki D and Sadoshima J: Is autophagy in response to ischemia and reperfusion protective or detrimental for the heart? Pediatr Cardiol 32: 275-281, 2011.

27. Biswas S, Roy S, Banerjee J, Hussain SR, Khanna S, Meenakshisundaram G, Kuppusamy P, Friedman A and Sen CK: Hypoxia inducible microRNA 210 attenuates keratinocyte proliferation and impairs closure in a murine model of ischemic wounds. Proc Natl Acad Sci USA 107: 6976-6981, 2010.

28. Devlin C, Greco S, Martelli F and Ivan M: miR-210: More than a silent player in hypoxia. IUBMB Life 63: 94-100, 2011.

29. Gee HE, Camps C, Buffa FM, Patiar S, Winter SC, Betts G Homer J, Corbridge R, Cox G, West CM, et al: hsa-mir-210 is a marker of tumor hypoxia and a prognostic factor in head and neck cancer. Cancer 116: 2148-2158, 2010.

30. Feng GM, Chen JH, Lin CI and Yang JM: Effect of docosahexaenoic acid on hypoxia/reoxygenation injury in human coronary arterial smooth muscle cells. Eur J Nutr 51: 987-995, 2012.

31. McCord JM: Oxygen-derived free radicals in postischemic tissue injury. N Engl J Med 312: 159-163, 1985.

32. Jensen FB, Hansen MN, Montesanti G and Wang T: Nitric oxide metabolites during anoxia and reoxygenation in the anoxiatolerant vertebrate Trachemys scripta. J Exp Biol 217: 423-431, 2014.

33. Robertson SJ, Mokgokong R, Kania KD, Guedj AS, Hladky SB and Barrand MA: Nitric oxide contributes to hypoxiareoxygenation-induced P-glycoprotein expression in rat brain endothelial cells. Cell Mol Neurobiol 31: 1103-1111, 2011.

34. Rus A, Molina F, Peinado MA and Del Moral ML: Nitric oxide averts hypoxia-induced damage during reoxygenation in rat heart. Microsc Res Tech 74: 1093-1103, 2011.

35. Kim JS, Wang JH and Lemasters JJ: Mitochondrial permeability transition in rat hepatocytes after anoxia/reoxygenation: Role of $\mathrm{Ca}^{2+}$-dependent mitochondrial formation of reactive oxygen species. Am J Physiol Gastrointest Liver Physiol 302: G723-G731, 2012

36. Kondoh M, Ohga N, Akiyama K, Hida Y, Maishi N, Towfik AM, Inoue N, Shindoh M and Hida K: Hypoxia-induced reactive oxygen species cause chromosomal abnormalities in endothelial cells in the tumor microenvironment. PLoS One 8: e80349, 2013.

37. Xu H, Yao Y, Su Z, Yang Y, Kao R, Martin CM and Rui T: Endogenous HMGB1 contributes to ischemia-reperfusioninduced myocardial apoptosis by potentiating the effect of TNF- $\alpha / J N K$. Am J Physiol Heart Circ Physiol 300: H913-H921, 2011.

38. Okuma Y, Liu K, Wake H, Liu R, Nishimura Y, Hui Z, Teshigawara K, Haruma J, Yamamoto Y, Yamamoto $\mathrm{H}$, et al: Glycyrrhizin inhibits traumatic brain injury by reducing HMGB1-RAGE interaction. Neuropharmacology 85: 18-26, 2014.

39. Su Z, Yin J, Wang T, Sun Y, Ni P, Ma R, Zhu H, Zheng D, Shen $\mathrm{H}, \mathrm{Xu} \mathrm{W}$, et al: Up-regulated HMGB1 in EAM directly led to collagen deposition by a PKC $\beta / E r k 1 / 2$-dependent pathway: Cardiac fibroblast/myofibroblast might be another source of HMGB1. J Cell Mol Med 18: 1740-1751, 2014.

40. Sun X and Tang D: HMGB1-dependent and -independent autophagy. Autophagy 10: 1873-1876, 2014.
41. Germani A, Foglio E, Capogrossi MC, Russo MA and Limana F: Generation of cardiac progenitor cells through epicardial to mesenchymal transition. J Mol Med Berl 93: 735-748, 2015.

42. Bi WR, Xu GT, Lv LX and Yang CQ: The ratio of transforming growth factor- $\beta 1$ /bone morphogenetic protein-7 in the progression of the epithelial-mesenchymal transition contributes to rat liver fibrosis. Genet Mol Res 13: 1005-1014, 2014.

43. Wen SL, Gao JH, Yang WJ, Lu YY, Tong H, Huang ZY, Liu ZX and Tang CW: Celecoxib attenuates hepatic cirrhosis through inhibition of epithelial-to-mesenchymal transition of hepatocytes. J Gastroenterol Hepatol 29: 1932-1942, 2014.

44. Sun S, Ning X, Zhai Y, Du R, Lu Y, He L, Li R, Wu W, Sun W and Wang H: Egr-1 mediates chronic hypoxia-induced renal interstitial fibrosis via the PKC/ERK pathway. Am J Nephrol 39: 436-448, 2014

45. Hale AN, Ledbetter DJ, Gawriluk TR and Rucker EB III: Autophagy: Regulation and role in development. Autophagy 9: 951-972, 2013.

46. Bánréti A, Sass M and Graba Y: The emerging role of acetylation in the regulation of autophagy. Autophagy 9: 819-829, 2013.

47. Guan JL, Simon AK, Prescott M, Menendez JA, Liu F, Wang F, Wang C, Wolvetang E, Vazquez-Martin A and Zhang J: Autophagy in stem cells. Autophagy 9: 830-849, 2013.

48. Zhang QY, Wu LQ, Zhang T, Han YF and Lin X: Autophagymediated HMGB1 release promotes gastric cancer cell survival via RAGE activation of extracellular signal-regulated kinases 1/2. Oncol Rep 33: 1630-1638, 2015.

49. Liu Y and Song L: HMGB1-induced autophagy in Schwann cells promotes neuroblastoma proliferation. Int J Clin Exp Pathol 8: 504-510, 2015.

50. Liu W, Zhang Z, Zhang Y, Chen X, Guo S, Lei Y, Xu Y, Ji C, Bi Z and Wang K: HMGB1-mediated autophagy modulates sensitivity of colorectal cancer cells to oxaliplatin via MEK/ERK signaling pathway. Cancer Biol Ther 16: 511-517, 2015.

51. Li X, Wang S, Chen Y, Liu G and Yang X: miR-22 targets the 3'UTR of HMGB1 and inhibits the HMGB1-associated autophagy in osteosarcoma cells during chemotherapy. Tumour Biol 35: 6021-6028, 2014

52. Yanai H, Matsuda A, An J, Koshiba R, Nishio J, Negishi H, Ikushima $\mathrm{H}$, Onoe T, Ohdan $\mathrm{H}$, Yoshida $\mathrm{N}$, et al: Conditional ablation of HMGB1 in mice reveals its protective function against endotoxemia and bacterial infection. Proc Natl Acad Sci USA 110: 20699-20704, 2013.

53. Yang M, Cao L, Xie M, Yu Y, Kang R, Yang L, Zhao M and Tang D: Chloroquine inhibits HMGB1 inflammatory signaling and protects mice from lethal sepsis. Biochem Pharmacol 86: 410-418, 2013.

54. Hagiwara S, Iwasaka H, Koga H, Hasegawa A, Kudo K, Kusaka J, Oyama Y and Noguchi T: Stimulation of autophagy in the liver by lipopolysaccharide-induced systemic inflammation in a rat model of diabetes mellitus. Biomed Res 31: 263-271, 2010.

55. Andersson KB, Florholmen G, Winer LH, Tonnessen T and Christensen G: Regulation of neuronal type genes in congestive heart failure rats. Acta Physiol (Oxf) 186: 17-27, 2006.

56. Agarwal G, Mihai $\mathrm{C}$ and Iscru DF: Interaction of discoidin domain receptor 1 with collagen type 1. J Mol Biol 367: 443-455, 2007.

57. Kothiwale S, Borza CM, Lowe EW Jr, Pozzi A and Meiler J: Discoidin domain receptor 1 (DDR1) kinase as target for structure-based drug discovery. Drug Discov Today 20: 255-261, 2015.

58. Iwai LK, Luczynski MT and Huang PH: Discoidin domain receptors: A proteomic portrait. Cell Mol Life Sci 71: 3269-3279, 2014.

59. Vogel WF, Abdulhussein R and Ford CE: Sensing extracellular matrix: An update on discoidin domain receptor function. Cell Signal 18: 1108-1116, 2006. 